Claremont Colleges

Scholarship@ Claremont

Pitzer Faculty Publications and Research

Pitzer Faculty Scholarship

4-1-2004

\title{
Cultural Standing in Expression of Opinion
}

Claudia Strauss

Pitzer College

Recommended Citation

CLAUDIA STRAUSS (2004). Cultural standing in expression of opinion. Language in Society, 33:2, pp. 161-194. doi:10.1017/ S004740450433201X

This Article is brought to you for free and open access by the Pitzer Faculty Scholarship at Scholarship @ Claremont. It has been accepted for inclusion in Pitzer Faculty Publications and Research by an authorized administrator of Scholarship @ Claremont. For more information, please contact scholarship@cuc.claremont.edu. 


\title{
Cultural standing in expression of opinion
}

\author{
CLAUDIA STRA S S \\ Department of Anthropology \\ Pitzer College \\ 1050 N. Mills Avenue \\ Claremont, CA 91711 \\ claudia_strauss@pitzer.edu
}

A B S T R A C T

This article explores an underappreciated pragmatic constraint on the expression of opinions: When expressing an opinion on a topic that has been previously discussed, a speaker should correctly indicate the cultural standing of that view in the relevant opinion community. This Bakhtinian approach to discourse analysis is contrasted with conversation analysis, politeness theory (Brown \& Levinson 1987), and analysis of epistemic modality. Finally, indicators of four points on the cultural standing continuum (highly controversial, debatable, common opinion, and taken for granted) are illustrated with examples from American English usage. (Opinion display, discourse analysis, argumentation, hedges, modality, welfare discourse)*

“... Prose discourse - in any of its forms, quotidian, rhetorical, scholarly_cannot fail to be oriented toward the 'already uttered,' the 'already known,' the 'common opinion' and so forth.” Mikhail Bakhtin, "Discourse in the Novel” (1981:279)

When speakers voice an opinion on a topic about which there has been prior discourse or tacit agreement in their opinion community, they are expected to mark the CULTURAL STANDING of that opinion. "Cultural standing" is my label for the location of a view on a continuum that ranges from highly controversial to completely taken for granted in the relevant opinion community. Cultural standing has been insufficiently discussed in pragmatics, sociolinguistics, and discourse analysis as a constraint on opinion display. Expression of opinion has been analyzed primarily from three perspectives: how conversations are structured (conversation analysis; e.g., Pomerantz 1984, Sacks 1987); how social relations of power and solidarity affect the expression of potentially offensive views (politeness theory; e.g., Brown \& Levinson 1987); and what evidence speakers have for their views (Chafe \& Nichols 1986). In this article I propose a Bakhtinian 
perspective (Bakhtin 1981) that looks at how speakers respond not only to evidence and to the immediate addressee, but also to previous social commentary on a given topic.

The following thought experiment may provide an intuitive grasp of the pragmatic principle that we should indicate correctly the perceived cultural standing of our opinions. Imagine someone who expresses a controversial or discredited view as if it were the common opinion or taken for granted - for example, Since the earth is flat, it follows that ... Or imagine the opposite, someone who expresses what is taken for granted as if it were controversial: You may think this is crazy, but you could almost say that it is important to be kind to others. There are probably misanthropic flat-earth adherents among whom the first proposition is the common opinion and the second one is not, but that is not the point here. Imagine hearers who do not think the earth is flat and just take for granted, rhetorically at least, the value of being kind to others. Such hearers would judge these speakers to be culturally or mentally incompetent, or - if the speaker appears to be a properly enculturated adult in possession of his or her faculties - the hearers would draw the implicature that they must be speaking ironically, metaphorically, wishfully, or playfully, because they could not possibly be serious. This shows the power of the expectation that speakers should correctly mark the perceived cultural standing of their opinions. ${ }^{1}$

More attention to cultural standing would benefit research in both language and culture. For years, anthropologists tended to focus on highly sedimented world views - those that are taken for granted or are the consensual common opinion. Recently, the tendency has been to focus instead on contested views. Clearly it is necessary to recognize both: In a given society at a given time, some ideas are up for grabs and others are more settled. (See Bourdieu 1977:168; Williams 1977:121-7; Comaroff \& Comaroff 1991:19-32; Strauss \& Quinn 1997: 36-41.) When a view is thought to have high cultural standing, so that it is generally considered to be the opinion that most people hold, it can be more powerful than the views that most people truly do hold, and the views that everyone thinks are controversial will be uttered only furtively if at all, reinforcing the view that no one holds them (Noelle-Neumann 1993). Paying attention to markers of cultural standing would be a way to explore this dynamic in a society at a given time, or to trace how the standing of a given idea has changed over time.

For sociolinguists and discourse analysts, attention to cultural standing would bring together many unconnected bodies of research. It would also shed light on aspects of discourse that have not been adequately explained by other approaches. In addition to conversation analysis and politeness theory, important contributions to the study of how opinions are expressed have been made by analysts looking at particular genres (e.g., argumentation and focus group conversation), particular discourse features (e.g., discourse markers like you know, evidentials, hedging, presuppositions, formulaic speech), particular topics (e.g., race and immigration), and related functions (e.g., epistemic modality). In this article, I show 
that some of these observations can be integrated in a model of markers of cultural standing, and others can be enriched by the model.

The article has four main sections. First, I review previous research to show that while cultural standing analysis owes a great deal to previous work, it is a different pragmatic constraint than the interpersonal considerations of politeness analysis or the epistemic factors marked by evidentials. After the literature review, I outline the cultural standing model and discuss the kinds of data I draw upon for evidence. There follows, in the longest section, a detailed description of cultural standing markers in American English. In the Conclusion, I discuss the cross-cultural applicability of the model as well as other ways in which context may affect its application.

\section{RELATED APPROACHES}

A review of conversation analysis, politeness theory, and critical linguists' discussions of epistemic modality will clarify both what the proposed model owes to previous discussions and what it can add to them. Other pertinent analyses (e.g., of argumentation or hedges) will be discussed as they become relevant to particular aspects of the cultural standing model.

\section{Conversation analysis}

Conversation analysts have discovered a preference for agreement in conversation, at least among English speakers. ${ }^{2}$ If Speaker A offers an assessment and Speaker B disagrees, B will try to avoid blatant disagreement. These analysts have perceptively noticed some of the strategies used, such as replying with a weak affirmation before disagreeing (Yes but), or otherwise delaying the potentially offending demurral with pauses or prefatory comments (Well ...) (Pomerantz 1984, Sacks 1987). Another way in which hearers respond to controversial opinions, they note, is through silence or "next-turn repair initiators," which invite the speaker to back down or correct a questionable statement (Schegloff, Jefferson \& Sacks 1977, Pomerantz 1984). However, conversation analysis is restricted in its ability to describe and explain markers of cultural standing because of its singleminded focus on the here-and-now of conversational interchange (as many critics have noted, e.g. Hymes 1974:81). ${ }^{3}$ In the simplified world of conversation analysis, speakers do not anticipate whether a hearer will agree or disagree on the basis of previous knowledge about the hearer or people like him or her. Instead, they react to the hearer's subtle indications of agreement or disagreement. This misses the preventive work that speakers do based on the cultural models they bring to the conversation.

Cultural models are learned, shared mental representations or schemas: both factual and value-laden assumptions about the world (Holland \& Quinn 1987, D'Andrade \& Strauss 1992, Strauss \& Quinn 1997). As cultural models theorists and other theorists of pragmatics have observed, for speakers these include assumptions about the hearer's beliefs (Sperber \& Wilson 1986; D'Andrade 
1987:113). Assumptions about hearers' views could be based on things they have said before. Frequently, however, assumptions about hearers' opinions are based on cultural models or schemas of what a person like that would think; as stereotypes based, for example, on clothing, age, sex, ethnicity, educational level, or lifestyle. These beliefs undergird the anticipatory work speakers do in conversation, modifying both how speakers phrase their assessments and whether they venture an assessment at all. As described further below, speakers may not offer an opinion in the first place if they suspect the hearer will view the statement either as obviously true or as outrageously false (see also Bourdieu 1977:18).

\section{Politeness theory}

Although Penelope Brown and Stephen Levinson's theory of politeness (1987) makes use of conversation analysis, they add to it the important element of the social relations of the speaker and addressee. Drawing on Goffman 1967, they argue that much of ordinary conversation is motivated by the speaker's concern for the addressee's "face wants." People everywhere, they say, want their actions to be unimpeded and (the point that is most relevant here) want their "wants [to] be desirable to at least some others" (Brown \& Levinson 1987:62). To put the second point more colloquially, they want their identities, values, and choices to be validated by others. This is relevant to the expression of opinions. Brown \& Levinson note that one possible "face-threatening act" (FTA) is "contradiction or disagreement" (p. 66) with the other's opinion. Unless the speaker (S) can afford to offend the hearer $(\mathrm{H})$ (because $\mathrm{S}$ is much more powerful than $\mathrm{H}$, or $\mathrm{S}$ does not need $\mathrm{H}$ to do a big favor for him or her), $\mathrm{S}$ will be careful about expressing opinions with which $\mathrm{H}$ might disagree. One way in which speakers avoid the FTA of disagreeing with their listeners is by discussing only "safe topics," such as "the weather ... the beauty of gardens, the incompetence of bureaucracies ... and the irritations of having to wait in line" (112). Drawing on the work of conversation analysis, Brown \& Levinson also mention strategies of softening dissent, as well as of hedging one's opinions with vague language such as sort of, kind of, like, in a way (as in I don't know, like I think. . ) (112-116).

Brown \& Levinson do not discuss the schemas that allow speakers to anticipate what hearers will find offensive, but they acknowledge that such anticipation occurs. Thus, they note that "the more $\mathrm{S}$ knows about $\mathrm{H}$, the more close to home will be the safe topics he can pursue with H" (112). It follows that sticking to conventionally safe topics is not always the most effective positive politeness strategy (i.e., one that highlights solidarity between $\mathrm{S}$ and $\mathrm{H}$ ). Instead, if you and your interlocutors see yourselves as belonging to a minority opinion community, it enhances solidarity to venture an opinion that is contested in the wider society but is the common opinion among people like you. ${ }^{4}$ This is much more effective than talking about safe topics like the weather as a way of satisfying listeners' desires to be validated in their opinions. ${ }^{5}$ Similarly, negative politeness requires 
that you avoid comments that you suspect have low cultural standing in H's opinion community. Of course, if contradicting the other's opinion is not a serious FTA in S and H's speech community, then these strategies are less needed, although cultural standing may still be indicated in other ways.

In certain respects, the cultural standing framework developed here differs from Brown \& Levinson's politeness theory. A minor problem is that, as Chen 2001 points out, Brown \& Levinson focus on the way speakers protect the hearer's face, while largely ignoring the way speakers also protect their own face (Goffman 1959). This is particularly relevant to the expression of cultural standing. In marking cultural standing, speakers are not just concerned to avoid offending the hearer. They are also protecting themselves from the judgment that they are unaware of or insensitive to group opinion. (See van Dijk 1987:86 on the importance of managing self-presentation in talk about ethnic minorities.) Chen 2001 shows that some modifications of Brown \& Levinson's politeness strategies are needed to accommodate what he calls "self-politeness." Still, I agree with Chen that speakers' concern with protecting their own face can be accommodated by an expanded politeness theory. (Brown \& Levinson raise this issue themselves, 1987:67-8.)

A more serious problem with politeness theory is that speakers are not always rationally attuned to face wants (whether H's or their own) in a particular context. Sometimes we are creatures of habit, and the way we talk about a topic is due to the way we usually hear that topic discussed, and the way we have discussed it before, rather than to a strategic assessment of what is advantageous. For example, in the following excerpt from a series of interviews I conducted on politicaleconomic issues, compare the way George Gauvin, ${ }^{6}$ a factory worker in his sixties, talks about "big money" and "the rich" in the first five pause groups versus the last. The topic was corporate tax loopholes. (Boldface indicates my emphasis; numbers in parentheses are pause lengths in seconds; my backchannels and other contextual information are in double parentheses; unintelligible portions of the tape are given by empty parentheses. ${ }^{7}$ ):

(1) Big money, boy. ((Mm)) (1.0) Can't beat it. (1.2) ((Mm)) Can't beat big money. (3.0) (( Mm, I know)) The rich get richer and the poor get poorer. (1.8) It's true. (1.8) ((Mm)) You probably got ( ) big money, I shouldn't talk like that.

The last line reflects politeness considerations. Suddenly it occurred to Gauvin that what he had said could have been offensive to me, so he apologized in a blatant concession to what he guessed to be my face wants. The blunt wording of the previous lines, by contrast, was not shaped by his speculation about my opinion but by the way that idea is commonly expressed in his opinion community. This view is in fact the common opinion among working-class speakers of his generation (as I found in my research), and is marked as such by the use of maxims, clichés, and other kinds of formulaic speech that express generalizations without any mitigation. 
On the whole, however, politeness and cultural standing models are complementary, in two senses. First, neither model is complete without the other. Cultural standing considerations affect speakers' judgments about what would be considered a possible FTA in the expression of opinions, and negative and positive politeness strategies for mitigating FTAs, while politeness considerations help explain why cultural standing is marked in discourse. Second, politeness and cultural standing models are complementary in the sense of focusing on different aspects of the context: Politeness is a SOCIAL phenomenon, while cultural standing is a CULTURAL phenomenon. In other words, while politeness markers reflect the interpersonal relations of the speaker and addressee, cultural standing markers reflect the background of values and beliefs in a community. Social and cultural aspects of the context are both important, as will be discussed further below, but some situations highlight considerations of politeness and others highlight those of cultural standing. If the situation is one that highlights considerations of cultural standing, politeness analysis will give a less incisive analysis of the discourse, and vice versa.

\section{Bakhtin, critical discourse analysis, and epistemic modality}

More than 60 years ago, Mikhail Bakhtin anticipated the main lines of my remarks above when he pointed out that there is a difference between the way the speaker accommodates to the listener and the way the speaker reacts to previous discourse about the object: "They differ in their essentials and give rise to varying stylistic effects in discourse" (Bakhtin 1981:283). ${ }^{8}$ This key insight, along with Bakhtin's attention to the way all discourse is "oriented toward the 'already uttered,' the 'already known,' the 'common opinion' and so forth” (1981:279), is the starting point for the cultural standing model developed below.

Also key to this analysis is the insight of Bakhtin and many other theorists that the cultural background of what has been previously thought and said is not fixed. What was the common opinion or even taken for granted at one time can be contested at a later time - or the reverse (e.g., Bourdieu 1977:168; Williams 1977; Bakhtin 1981:345-8).

The way shifting ideologies are reflected in discourse is the focus of discussions of modality by critical linguists (e.g., Kress \& Hodge 1979, Hodge \& Kress 1988) and critical discourse analysts (e.g., Fairclough 1992:158). Lyons's definition of epistemic modality is a useful starting point:

Any utterance in which the speaker explicitly qualifies his commitment to the truth of the proposition expressed by the sentence he utters, whether this qualification is made explicit in the verbal component, as in [He may have gone to Paris, Perhaps he went to Paris, It's possible that he went to Paris] or in the prosodic or paralinguistic component, is an epistemically modal, or modalized, utterance. (Lyons 1977:797) 
(See also Halliday 1976:192 on modality defined as "the speaker's assessment of the probability of what he is saying, or the extent to which he regards it as selfevident.") For critical linguists and discourse analysts, "Modality points to the social construction or contestation of knowledge-systems. Agreement confers the status of 'knowledge', 'fact' on the system, or on aspects of it; lack of agreement casts that status into doubt ... Modality is consequently one of the crucial indicators of political struggle" (Hodge \& Kress 1988:123). These theorists note that speakers cannot avoid indicating their commitment to the propositions they state: "In any propositional utterance, the producer must indicate what Hodge \& Kress (1988:123) call a degree of 'affinity' with the proposition" (Fairclough 1992:158).

Outside of critical discourse analysis, there has also been considerable work on epistemic modality in the growing literature on evidential markings, the ways in which speakers mark the type of evidence they have for their assertion and the degree of certainty they give it (e.g., Chafe \& Nichols 1986). For example, Talmy Givón claims that evidentials in KinyaRwanda, Sherpa, and Ute indicate a universal tendency to distinguish the following three sorts of propositions:

(a) Propositions which are to be taken for granted, via the force of diverse conventions, as unchallengeable by the hearer and thus requiring no evidentiary justifications by the speaker;

(b) Propositions that are asserted with relative confidence, are open to challenge by the hearer and thus require - or admit - evidentiary justification; and, finally,

(c) Proposition [s] that are asserted with doubt, as hypotheses, and are thus beneath both challenge and evidentiary substantiation. They are, in terms of the implicit communicative contract, "not worth the trouble." $(1982: 24)^{9}$

The cultural standing model presented below builds on this work by distinguishing cultural standing from interpersonal (politeness) and epistemic factors affecting speakers' commitment to an utterance. Previous work on modalization does not distinguish among these, but it is useful to do so because modalizers have different pragmatic meanings depending upon which of these functions (epistemic, politeness, cultural standing) they serve in a given context. Compare examples (2-4). In each case, the speaker modalizes, but the way in which this is to be interpreted differs. (Modalizers are in boldface.)

\section{Epistemic modalization}

(2) Discussion about whether our college-age daughter, who was not present, would join us for a family vacation the following summer.

CS: Po:ssibly Rachel will come.

In this case I (CS) indicate low commitment to the proposition because it is hard to predict the summer vacation plans of a 19-year-old a year in advance. I 
doubted that Rachel would come, but I could not say for sure because I did not know. I will reserve the term "epistemic modalization" for the speaker's qualifications regarding the certainty of the facts. ${ }^{10}$

\section{Modalizing for politeness}

(3) Discussion with a cab driver (CD) about construction across the street from my house. The driver had an unobstructed view of the work for several minutes before I (CS) got into the cab. CD: They're building a new wall.

CS: I thought they were doing something to the street.

CD: They're building a wall. Or-whatever. They're building something. God only knows what they're building.

In this case, the problem is not insufficient knowledge: The cab driver has no doubt that they are building a wall. The pragmatic meaning of the modalizers (whatever, something, God only knows) is "I don't want to get into an argument about it with a customer."

\section{Modalizing to express cultural standing}

(4) The last sentence of a U.S. News \& World Report article on the health effects of the drug ecstasy.

Evidence suggests that perhaps some day a designer drug based on ecstasy may be developed that could provide potential psychological benefits-without the scary side effects. (Boyce 2001) ${ }^{11}$

One reason for the extensive modalization in (4) is that the facts are uncertain (epistemic modalization). But another reason is that the writer must be aware that it is controversial, in the opinion community represented by U.S. News \& World Report readers, to say that illegal drugs could have benefits. Her modalization reflects her awareness of the view's weak cultural standing.

As the last example indicates, sometimes a speaker's commitment to a proposition is affected by a combination of epistemic, politeness, and cultural standing considerations. Different situations bring different combinations of these considerations to the fore, and it is important to think about which are most significant in a given instance. Academic journal articles, for example, are a genre in which the cultural standing of the author's views in the relevant community of scholars is a highly salient constraint, at least as salient as epistemic concerns and more so than interpersonal ones. Even when most concerned about possible FTAs (e.g., thinking about the opinions of the editor or potential reviewers), scholars anticipate a response on the basis of schemas about how controversial or accepted their views are in various scholarly communities. The choice of a politeness or cultural standing analysis of academic writing makes a difference when one is analyzing the significance of intensifiers such as really, actually, obviously, surely and indeed in this context. Hyland 1998 and Myers 1989 argue that, in academic articles, intensifiers are "positive-politeness devices, enabling 
writers to assume shared ground with their readers and stress common group membership" (Hyland 1998:353).

The cultural standing model presented below, however, gives a very different interpretation of intensifiers. In a context of opinion display, intensifiers are markers of debate because the speaker intensifies to strengthen the argument in the face of anticipated criticism (see Schiffrin 1985:40). That seems a better analysis of the examples of intensifiers in academic writing that Hyland gives (e.g., This brings us into conflict with Currie's account, for static images SURELY cannot trigger our capacity to recognize movement, quoted in Hyland 1998:350).

Similarly, hedges are very common in academic writing not only because we are expected to be careful about acknowledging the limits of what can be concluded from our data (epistemic concerns) and because we want to avoid personal offense (politeness concerns), but also because we are expected to acknowledge that there are competing views in the literature (cultural standing concerns, as Hyland also recognizes; e.g., 1998:351 ${ }^{12}$; see also Salager-Meyer et al. 1996:164).

A similar caution should be raised about Givón's analysis of evidentials. While the evidentiary justification needed for propositions that are "taken for granted" and those that are "asserted with relative confidence" apply as well to a cultural standing analysis, there is a significant divergence between propositions he describes as "asserted with doubt, as hypotheses" (because they have weak epistemic justification) and those with weak cultural standing. Propositions asserted with doubt because they have weak epistemic justification are "beneath both challenge and evidentiary substantiation" because speakers realize they are " "not worth the trouble'," according to Givón (1982:24). Quite the opposite happens in the case of a proposition that is controversial because of its weak cultural standing: As I will show below, in such cases speakers engage in extensive preventive measures because they know the statement may well be challenged.

Fundamentally, discussions of evidentials (expression of speaker's evidence) and modalization (expression of speaker's commitment or detachment) do not account for markers of cultural standing (expression of speaker's view of the acceptability of an idea in the salient opinion community) because these are different phenomena. Speakers can simultaneously express high personal commitment and low cultural standing, or the reverse, as in this so-called improvement in the standard of living (quoted in Stubbs 1996:208). ${ }^{13}$ In this example, so-called simultaneously indicates high cultural standing (it is widely said that there has been an improvement) and low speaker adherence.

THE CULTURALSTANDING MODEL

Some of the main points of my model of cultural standing are as follows. Cultural standing is a continuum, ranging from the highly controversial to what is so widely accepted that it is not even acknowledged as a proposition about which one could have alternative opinions. This model was greatly influenced by Pierre 
Bourdieu's discussion of the difference between DOGMA (the "universe of discourse [or argument]") and Doxa (the "universe of the undiscussed [undisputed]"; 1977:168). He further divides the realm of dogma into orthodoxy (the dominant ideology) and heterodoxy (views that contest the reigning orthodoxy). It is important to keep in mind the distinction Bourdieu makes between the reigning orthodoxy, which is widely believed in an explicit way, and what is doxic, which is so much taken for granted that it does not need to be spoken, because in cultural analysis this distinction is frequently elided. ${ }^{14}$ Bourdieu's categories could be ordered as follows, moving from views with the lowest cultural standing (most controversial) on the left to those with the highest cultural standing (most accepted) on the right ${ }^{15}$ :

\section{Heterodoxy - Orthodoxy - Doxa}

The present discussion modifies Bourdieu's framework by recognizing four major points, instead of three, along the continuum of cultural standing. Between Bourdieu's categories of heterodoxy (which I label the CONTROVERSIAL OPINION) and orthodoxy (which I label the COMMON OPINION), I add a zone of contested but not so highly controversial opinions, which I call the DEBATABLE OPINION. This is the realm in which it is acknowledged that there are legitimate alternative points of view, corresponding to Givón's propositions that are "open to challenge." The extra category is necessary because opinions at these different points are expressed in distinctive ways. ${ }^{16}$

\section{Controversial opinion - Debatable opinion - Common opinion - Taken for granted}

Another way in which this cultural standing model differs from Bourdieu's is that in his scheme these are sharply defined categories: Doxic beliefs are unsaid, while heterodox and orthodox ones are said. No such hard and fast distinction will be made here. An examination of discourse reveals a gradual continuum rather than a sharp boundary between what is said and what is unsaid. It is possible to bring the unsaid to awareness and express it, but in the normal course of events that rarely happens (Strauss \& Quinn 1997:46).

Cultural standing is relative in that what is controversial in one opinion community could be the common opinion in another. An opinion community is any social group, of any size, in which opinions are discussed (or, at the taken-forgranted end, in which assumptions are shared). It can be a face-to-face group like a family, social clique, or local community, or a far-flung one in which various media - electronic chat rooms, newspapers, music, movies, and television - mediate the discussion. Opinion communities are formed by prior discussion of a topic, and familiarity with this prior discussion is part of the expected competence of members of that community. ${ }^{17}$ 
Not all opinions have a cultural standing in a given social group. To have a cultural standing, a proposition has to have been the topic of prior discourse or agreement. The requirement of prior discourse rules out matters of only passing interest. Many opinions (e.g., That's a nice shirt. What a beautiful sunset.) concern matters that are not topics of general discussion; hence, their expression is governed by purely referential considerations and politeness more than by cultural standing. Similarly, examples (2) and (3) above fall into the category of propositions without cultural standing, because there was no prior discourse about those topics with which we, the speakers, had to contend. Note, however, that a matter need not be a weighty national issue to be important to some group of people and become a topic of discussion. The issue of whether our daughter would join us for a family vacation (ex. 2) had not been previously discussed, but if we had continued to discuss it because it was important to us, then it would have acquired a standing in the opinion community constituted by our family.

Complicating this analysis is the fact that the way S marks the cultural standing of an opinion depends not on the established cultural standing of that opinion in S's or H's opinion communities but on S's assumptions about its cultural standing. As Perelman \& Olbrechts-Tyteca note, "The reference group. .. may be considered in different ways. Sometimes one thinks of the ... opinion of those regarded as spokesmen for this common opinion or of what is commonly considered to be the opinion of the spokesmen" (1969:72).

Speakers may overgeneralize and assume that all members of a sex, nationality, ethnicity, or generation share the opinions of the most vocal representatives of those groups. If there is no widespread awareness of what the state of discussion has been, speakers who confidently express a point of view as if it were the common opinion can lead everyone else to treat that view as the common opinion. By the same token, in a small opinion community only one person disputing a view that was previously unquestioned may be enough to disrupt the assumption that it is the common opinion. However, that tactic can backfire if the speaker does not have an assured enough position in the group to carry this off. Perelman $\&$ Obrechts-Tyteca further point out:

[The reference group] is highly unstable. Indeed, if certain individuals diverge in behavior from what is regarded as normal, their conduct may modify the norm ... But if a person deviates beyond certain limits, he will be excluded from the group, and the reference group will be modified. (1969:72)

A further complication is that the way speakers mark cultural standing depends on which opinion community is salient for them as they are forming their utterance. There are several possibilities: the opinion communities that shaped S's own opinion, the opinion communities to which $\mathrm{S}$ and $\mathrm{H}$ both seem to belong, $\mathrm{H}$ 's opinion communities (if those are different from S's), the opinion of most people, or the opinion of the most influential people in society at large. Salience is dependent on situation and topic (e.g., shifting the topic from gender inequality to 
religion may shift the salient opinion community). Although this might seem to be a problem for the model, in practice it is not difficult to tell, for a given utterance, which of these opinion communities was most salient. This issue is taken up again in the Conclusion.

Why does the cultural standing of an opinion affect the way people talk about it? There are probably various general reasons for this. Opinion norms are like behavioral norms. Members of a community do not automatically follow them, but they are expected to know them, and if they deviate, to acknowledge that somehow. Not to do so is to signal that one does not know or care about the group's opinion. Thus, at the controversial and debatable end of the continuum, marking cultural standing is important for management of self-presentation. If the cultural standing of a view is different for speaker and hearer, or the same for speaker and hearer but different from the common opinion in the larger society, acknowledging this fact is necessary for positive or negative politeness. The way a speaker marks cultural standing for a particular addressee is a prime rhetorical means of creating a "subject position" - that is, of representing self and other as certain kinds of people (e.g., people who take certain stances for granted). Finally, in situations where speakers and hearers share the same views, and share the views of their wider opinion communities as well, further comment would be pointless. Thus, at the taken-for-granted end, the second half of Grice's Maxim of Quantity is in effect: "Make your contribution as informative as is required for the current purposes of the exchange; do not make your contribution more informative than is required." Whether cultural standing markers are a deliberate signal or simply embedded in habitual phrasing, they can still serve as an INDEX of cultural standing, and hence be useful for cultural analysis.

\section{DISCOURSE FOR OPINION DISPLAY}

The majority of examples used below to illustrate the model of cultural standing are drawn from genres the primary purpose of which is opinion display (Myers 1998:103). Some examples of these in speech are opinion statements elicited through interviews, focus groups, debates at meetings, talk radio, political speeches, "soapbox oration" (McIlvenny 1996), and assessments in casual conversation. Written genres that have the primary purpose of opinion display include letters to the editor, editorials, op-ed essays, on-line bulletin board postings, interpretations of research in academic prose, and other argumentative writing. Opinions are embedded as well in other genres that do not have opinion display as their primary function: such as gossip and narratives, where they are part of the narrative evaluation as well as the audience's commentary; expository prose, as in textbooks; opinion surveys, the wording of which betrays what is taken for granted and what is disputed at the time; jokes, many of which are funny only if the joke teller and audience share certain opinions; and even fiction, where the way characters comment or do not comment on various issues reflects their cul- 
tural standing in the author's and intended audience's opinion communities. The effect of genre on markers of cultural standing is discussed in the Conclusion.

Many of the examples below were drawn from discussions that I elicited in semistructured interviews and focus groups or that I encountered in various media (talk radio, on-line bulletin boards, and newspaper editorials) in the mid1990s on the topic of welfare reform in the United States - that is, changes to the system of cash aid to poor people. ${ }^{18}$ Radical revisions to federal welfare legislation were being debated at that time, and the topic was frequently in the news. The common opinion in the country at that time, as revealed by opinion polls and evident from casual conversation, was that the welfare system needed to be changed because it rewarded laziness and out-of-wedlock births, especially among racial minorities and immigrants. Also common, but perceived as more debatable, was the view that it is important to provide education and positive incentives for work. More controversial opinions were that of the Marxist left that it is good to keep people out of the workforce because that drives up wages, and that of the far right that government aid for poor people should be eliminated. ${ }^{19}$ Additional examples for analysis were drawn opportunistically from comments on other topics under debate nationally or locally.

\section{INDICATORS OF CULTURAL STANDING}

Many of the linguistic and paralinguistic features discussed below have been noticed by other discourse analysts. The purpose of the following discussion is to draw together these scattered observations into an overall model of cultural standing, as well as to propose some additional markers that have not been previously discussed, to my knowledge. Several caveats need to be kept in mind about these indicators. First, all of these should be taken as only prima facie indices that need to be judged in context: Differences between speakers and genres can lead to different results. (For example, some speakers could have a more hesitant and others a more confident style.) It could also happen that an utterance mixes markers from different cultural standing categories. This could happen, for example, if the cultural standing of the view is not clear (e.g., the speaker sees it as somewhere between debatable and the common opinion). In that case, however, the view should be expressed with markers from adjacent categories. Markers from nonadjacent categories should be mixed in an utterance only if they mark different propositions, or if the speaker changes his or her mind about the cultural standing of the view while talking (perhaps as a result of nonverbal signals from the addressee), in which case there should be other signs of a change of mind. Also, each of these categories covers a continuum; for example, "controversial opinions" covers a range from the highly controversial to the somewhat controversial. As was stated previously, judgments of standing are always relative to a particular opinion community, and what counts is the judgment of the speaker about what is controversial, debatable, and so on, not ours as outside analysts. 
Finally, the following description of cultural standing markers is based on analysis of American English, and other sorts of markers may be used in other dialects and languages (see Conclusion).

\section{Controversial opinions}

When speakers believe their opinions to be controversial, they will try to soften their statements in various ways to make them seem less out of step with the common opinion. This is commonly done by (i) self-censoring, or using euphemisms or other indirect language; (ii) denial; (iii) hedges; (iv) attribution to others, or use of the impersonal second or third person; (v) lamination; (vi) apologies, requests for permission, preemptive concession, and other verbal acknowledgments of uneasiness; (vii) self-initiated repairs; and (viii) pauses, disfluency, hesitation, and other prosodic and paralinguistic signs of discomfort. Teun van Dijk (1987:91-6) names several of these strategies (use of indirect language, denial, mitigation, attribution to others, self correction, avoidance, concession) as typical "moves" in expression of ethnic prejudice in both the Netherlands and the United States. There is also overlap with negative politeness and off-record discourse strategies (indirect language, giving hints, hedging, use of impersonal pronouns, apologies; see Brown \& Levinson 1987), markers of dispreferred seconds in conversation analysis (e.g., pauses, fillers, and apologies; Sacks 1987), and discussion of difficult topics in psychotherapy (indirect language, mitigation, hesitation, and disfluency; Labov \& Fanshel 1977).

Self-censoring or using euphemisms or other indirect language Sometimes S will simply refrain from directly stating a controversial opinion. We can guess these censored views by seeing what $\mathrm{S}$ or speakers like $\mathrm{S}$ say in other contexts, and by decoding the hints in vague or allusive language (Labov \& Fanshel 1977:287; van Dijk 1987: 95, 100-1).

(5) CS had asked Daniel Collins, a factory worker, what he thought about socialism.

DC: I'd rather not go into that. ..It might get into different things.

CS: ((Long pause to see if DC would say more)) I remember you saying last time that there's no freedom of speech; people call you a radical.

DC: ((Nods))

CS: Because, actually, what you were talking about with the government owning the utilities and so on sounds like democratic socialism in Europe.

DC: $((\text { Nods }))^{20}$

It seemed clear that Collins did not want to be tape-recorded saying that he is a socialist.

Denial As van Dijk points out, "One of the most stereotypical moves used in prejudiced talk is Apparent Denial, which usually contains a general denial of (one's own) negative opinions about ethnic groups, followed by a negative opinion: 'I am not a racist, but ...,' or 'I have nothing against foreigners, but ...'," (1987:91; see also Hewitt \& Stokes 1975 on disclaimers, especially their discus- 
sion of "credentialing," and Overstreet \& Yule 2001). ${ }^{21}$ Whether or not a speaker really believes what he denies believing is irrelevant in a cultural standing analysis. Either way, such denials are a strong indicator of a controversial position:

(6) Newspaper interview with chief health director in Washington, DC, about delays in testing postal workers for inhalation anthrax (Garvey \& Rosenblatt 2001:A15).

"No one was put aside because they weren't important or didn't work on Capitol Hill," said Walks.

Hedges Hedges are notoriously hard to define (e.g., Markkanen \& Schröder 1997). George Lakoff defined hedges as "words whose job is to make things fuzzier or less fuzzy" (1972:195). Since then, the concept has expanded beyond Lakoff's concern with the fuzziness of category membership in particular. I will use "hedge" for words (e.g., probably), phrases (It is possible that), syntax (e.g., use of the subjunctive modal auxiliaries could or might, or of double negatives that are to be interpreted as weaker positives, such as not unhealthy), and rhetorical strategies (e.g., understatement; van Dijk 1987:95) that are conventionally used to modalize. ${ }^{22}$ In spoken and written English, a common function of hedges is to soften controversial statements (on mitigation, see Labov \& Fanshel 1977: 287 and van Dijk 1987:95-6, 100-1). ${ }^{23}$ A single hedge word could indicate that the speaker sees the view as debatable rather than controversial, but multiple hedges, or hedges in conjunction with the other indicators listed here, are markers of controversial opinions.

(7) The last sentence of a U.S. News \& World Report article on the health effects of the drug ecstasy (Boyce 2001) (see ex. 4).

Evidence suggests that perhaps some day a designer drug based on ecstasy may be developed that could provide potential psychological benefits-without the scary side effects.

(8) Comment after approximately 40 minutes of focus group conversation among middle-aged white women, in which no one mentioned racial discrimination as a cause of poverty.

CS: How about, some people would say discrimination against minorities?

((Unresponsive body language from the group))

African-Americans and other groups that would account for poverty? (1.0)

What does anybody think about that? (1.9)

Judy: I think that's (.8) probably pretty sure.

(9) Interview with Nancy Goodall. She had stated that the media and government deliberately present a negative view of welfare recipients, and I asked why.

((Sigh)) Well (2.9) if you want to get into a real paranoid view you could almost say that (2.2) um (2.8) well, you've probably read Big Brother, 1984 ((Um-hm)) and, um, if you can divert people's focus (2.4) from problems that perhaps would be a little more difficult to address (1.3), um, you can divert them.

Attribution to others, or the impersonal second or third person, or unnamed agents Myers notices that in focus group conversation, sometimes a "view is presented as ONE SCHOOL OF THOUGHT - a possible view" rather than the speaker's own (1998:104). Myers proposes that presenting a view that is not necessarily the speaker's own is a way of making sure that a focus group fulfills its function of getting a variety of views out for discussion. Speakers also do this when they 
pronounce a view that they suspect is controversial (van Dijk 1987:98). It is a standard rhetorical ploy to attribute one's ideas to someone respected who can lend weight to the controversial proposal. However, sometimes a view is attributed to someone with no particular authority who is named as the source so that $\mathrm{S}$ can test the waters, putting a view out for H's reaction without aligning herself with it (Goffman 1974:512). An example of this seems to occur in the following conversation I held with a flight attendant (FA) after I noticed she was reading an article in People magazine about a high school Spanish teacher who mocked a boy in his class with pierced ears.

(10) FA: His Spanish teacher said, "There are only two types of men who pierce their ears. ((lowers voice)) Fags ((resuming normal volume)) and pirates. And since I don't see any water around here..."

CS: ((Silence, no encouragement))

FA: Which I think was totally out of line.

((A few minutes later, she repeated the same line to another flight attendant in a conspiratorial tone, and both of them laughed.))

Alternatively, attribution can be to an unnamed agent (It could be said that) or to the impersonal second or third person (You might say, One could say; cf. Brown \& Levinson 1987:194ff). Notice also the typical use of the modal auxiliaries might or could in the potential subjunctive mood in these constructions ${ }^{24}$ :

(11) One could conclude, if one was in a very bad mood, that it is not in the interests of affluent feminists to see the wages of working-class women improve. (Ehrenreich 2000)

(12) Interview with Nancy Goodall (see ex. 9).

((Sigh)) Well (2.9) if you want to get into a real paranoid view you could almost say that ...

Lamination Erving Goffman points out that there can be a layering, or "lamination," of selves in discourse (1974:516-23; see also Hill \& Zepeda 1992, Balaban 2000). One common way of modalizing controversial views is for S to signal that, to use Goffman's terms, the "principal" (originator) of a certain view is a less responsible version of one's self and, since the speaker is aware of this, the principal can be distinguished from the encompassing "addressing self" ("the one ... currently responsible and accessible to the listener," 1974:520). Diminished responsibility for one's views can be explained in any number of ways (e.g., crankiness, intoxication, youthful error, temporary insanity). This is the principle that if you can recognize that your behavior is crazy, then you are not really crazy (p. 521).

(13) One could conclude, if one was in a very bad mood, that it is not in the interests of affluent feminists to see the wages of working-class women improve. (Ehrenreich 2000)

(14) Interview with Nancy Goodall (see ex. 9). ((Sigh)) Well (2.9) if you want to get into a real paranoid view you could almost say that ...

(15) Prelude to a comment at a faculty meeting, following presentation of an exciting campus building plan.

Maybe I'm getting old and my back hurts so I'm going to say this in an inflammatory way but [we shouldn't be considering a new blade of grass or new brick if we can't make sure that we have financial aid for all the students who want to be here]. 
Preemptive concessions, apologies, requests for permission, and other verbal acknowledgments of uneasiness Related to lamination (in which the speaker admits being crazy, for example) is preemptive concession, in which the speaker allows that others might think the idea to be expressed is crazy, simplistic, wrongheaded, and so on.

(16) Interview with Joan Morse. I had asked how her ideal system would work. Well the obvious um (1.7) I heard somebody say-this is very simplistic and don't throw anything at me-but the solution to the homeless is to send them home.

(17) Prelude to suggestion in a faculty committee meeting. I'm just trying this out, okay? Go ahead and shoot me down.

(18) Prelude to comment at a faculty meeting. This is going to be unpopular.

Sometimes speakers apologize or ritualistically ask the listener's permission before using controversial language. Interestingly, the verbal formulae used are the same as or similar to the ones used in connection with taboo words. These apologies or requests are cultural standing markers if, as in (19) and (20) below, what is really controversial is not the words so much as the ideas expressed by them.

(19) Discussion by Ann Fagan Ginger, Executive Director, Meiklejohn Civil Liberties Institute, on a radio program, The Lawyer's Guild, of a proposal to use military tribunals to try prisoners in the war on terrorism.

We have, if you will excuse the expression, men [in positions of power and influence, showing poor judgment].

(20) Radio interview, Studs Terkel, quoted in an article defending humanism (Ruddick 2001:B8). We're facing a certain challenging moment as though it were a test for us, a test of our intelligence as well as our, may I use the word, humanity.

Speakers may otherwise verbally indicate their unease with expressing a controversial view. These are all examples of the more general practice, noticed by conversation analysts, of postponing disagreement, such as the use of Well followed by a long pause in (9) (Sacks 1987; see also van Dijk 1987:98 on "avoidance moves").

(21) Anonymous bioethicist, quoted in the New York Times, 2 Dec. 2001, 4:4. ${ }^{25}$

I don't know how to say this, but in my heart of hearts, I don't think cloning is inherently wrong.

Self-initiated repair Listed above are a number of ways in which speakers indicate their awareness that their views are controversial before they voice them. Sometimes, instead, the apology or concession comes as a self-initiated repair (Schegloff et al. 1977) right after a speaker makes a comment that he belatedly realizes is controversial. Van Dijk notes, "Corrections ... are interview features that are typical for the spontaneous nature of 'delicate' talk, as in 'maybe 'civilized' isn't the right word'" (1987:96). Self-initiated repairs do not always indicate a controversial opinion; the analyst's background knowledge is needed to judge if they do. 
(22) Interview with Mathew Healey. He was discussing whether the United States should have two official languages.

If there are more Spanish people in the country than there are, you know, more Spanishspeaking people than Americans, then-oh that was riddled with political incorrectness ((CS laughs))-but uh (.9) with more English-, more Spanish-speaking than Englishspeaking, then okay, it would make sense to have a bilingual country.

Pauses, disfluency, and other prosodic and paralinguistic hesitation markers Similarly, when speakers are preparing to state controversial views, very often they hesitate, stumble over their words, whisper, stretch out their words ${ }^{26}$ or rush them together, and otherwise nonverbally signal their awareness that their view is problematic (Labov \& Fanshel 1977, esp. chap. 9; Pomerantz 1984:70ff.; see Hill n.d. on disfluency). In (23) below, the speaker is a woman who moved to Burlington, North Carolina, as an adult and sees herself as different from most of the people there. She probably guessed that I would share her dim view of "rednecks," so her hesitation is more likely due to the controversial nature of her opinions in her opinion community (her friends are much more conservative than she is) than to concern about offending me.

(23) Interview with Bess Phillips for background information about Burlington, North Carolina. I think uh (1.6) I don't know if you can accept it. (.5) ((More quietly)) but I think a lot of (.7) a lot of people (3.4) ((Rolls eyes, grimaces, whispers)) are kind of redneck. You know?

(24) Interview with Nancy Goodall.

I'd pro::bably be happy with an overall ban of handguns.

For another example, see Nancy Goodall's comments in (9), which in addition to all the other markers of a controversial opinion already noted, also include a sigh, verbal fillers, and long pauses.

\section{Debatable opinion}

Unlike a controversial opinion, a view that the speaker sees as a DEBATABLE OPINION is expressed with more openness and less hesitation. Unlike the common opinion, however, it is still uttered defensively and shows the signs of dispute in the prior social discourse. Deborah Schiffrin's analysis of "rhetorical argument," "a discourse genre in which the speaker establishes ... a position that is potentially disputable"(1985:40)—is particularly apropos here. Unlike "oppositional argument," where the opponent is present (1985:41), in rhetorical argumentation an opponent is imagined. Schiffrin (1985:39-40) discusses each of the following ways in which orientation toward an imagined opponent gives this discourse its characteristic features: (i) there is a statement of position and support; (ii) views are qualified as the speaker's own beliefs; and (iii) there is comparison with alternative beliefs. Sometimes there is (iv) use of intensifiers.

Statement of position and support Giving support for a position is a strong indicator that it has questionable cultural standing. If the view were widely shared, it would not need defense. ${ }^{27}$ 
(25) Newspaper story by a local columnist sympathetic to protesters who were opposed to Rhode Island's support for an expensive convention center at a time when cuts were being made in public assistance (Kerr 1993:E1).

The Convention Center has to be questioned and challenged. [POSITION]

It simply sucks up too much public money in the midst of hard times not to be. [SUPPORT]

(26) Talk radio discussion of welfare. The caller is concerned about new regulations that will give people who are sick or disabled only three months of temporary welfare coverage, even if the disability coverage is not yet available.

I'm terrified of the suicides that I know is going to come down the line [SUPPORT] with this, I believe, irresponsible decision. [POSITION]

View qualified as the speaker's own belief If a position seems to be debatable, speakers often do not flatly assert it as true; instead, they frame it as their opinion using phrases like I think, I believe, to me, to my way of thinking, and so on. ${ }^{28}$ Note, however, that unlike what they do when offering controversial positions, speakers are more likely to "own" the view by using the first person and present tense (I believe, I feel, and I think) rather than impersonal second person, third person, or agentless constructions in the potential mood ( you could say, one might say, or it could be said). (See also Goffman 1974: 531, 1981:285; Stubbs 1983:186-7.) Note that self-attribution versus other-attribution does not always differentiate controversial from debatable opinions; see (8) and (23) for examples in which I think is used to qualify a position that the speaker otherwise treats as controversial, or perhaps somewhere between controversial and debatable.

(27) Comment in focus group of middle-aged white women.

Elaine: I think our welfare system could offer more incentives to people to work. I think that's the problem.

(28) Comment by caller in talk-radio discussion of welfare.

I'm terrified of the suicides that I know is going to come down the line with this, I believe, irresponsible decision.

(29) Comment in focus group of middle-aged white women.

Suzanne: I' $m$ a child of the sixties and I really feel almost personally responsible for bringing on the age of "drugs and sex and rock n' roll," because we blew away every value that was, we left nothing standing, and now I have teenage children and this is our fault.

(30) Comment about welfare recipients in focus group of middle-aged white women.

Betty: Someone said something about pride earlier on. That to me is a big beef too.

Comparison with alternative beliefs When speakers see their views as debatable, they are aware of competing views that are also considered legitimate in the opinion community. Sometimes those competing views are mentioned explicitly, as in the following example:

(31) Letter to the editor (James Haddad, Providence Journal, 10/30/93).

In the [newspaper] story, Senator York expressed outrage over the recent cuts in Rhode Island's General Public Assistance program. To quote Senator York: "Government should be able to help those least able to take care of themselves."

This rhetoric has been repeatedly uttered by liberals since the days of President Johnson's Great Society program. Unfortunately, history has shown that most government programs designed to "help those least able to take care of themselves" have failed miserably. 
Sometimes opposing views are indicated more indirectly. One way in which competing views are alluded to is through NEGATION. As Kress \& Hodge point out, if someone says, "There isn't a tiger in that room," the speaker "(and we as hearers) must have thought of a tiger being there first, before the proposition has been understood in its negative form" (1979:145; see also Perelman \& OlbrechtsTyteca 1969:155; Labov \& Fanshel 1977:104).

Alternatively, the proposed view could be put as a QUESTION, a negative response to which would give the competing view, as in (32):

(32) Cover of a mainstream magazine, Parade, an insert in many U.S. Sunday newspapers ( $\mathrm{Pa}$ rade, 19 May 2002).

Attorney General John Ashcroft is taking firm steps to thwart terrorism.

Understandably, his efforts provoke a critical question: Has America's Top Cop Gone Too Far?

Another indirect way of presenting competing views is by REPRESENTING THE VOICE OF THE CRITIC (where "voice" is used here in Bakhtin's [1981] sense to mean the discourse characteristic of a speaker; see also Hill 1995). In (33), Mathew Healey, a defender of traditional nuclear families, carries on an argument with the borrowed voice of a critic ("Okay, well define what a family is"), conceding some of the critic's points ("with all of its problems"):

(33) Interview with Mathew Healey.

And I really think family structure is important. And you can be attacked, Okay, well define what a family is. What a family was and had worked for however many thousands of years, with all of its problems.

CONTRASTIVE STRESS (selective emphasis in speaking, font changes in writing) can be used to highlight ideas the speaker feels are different from what has been said already (Schiffrin 1985):

(34) On-line bulletin board discussion of welfare (capitalization in the original).

Welfare has become a way of life. It can't be salvaged, instead it should be ABOLISHED with a new system for TEMPORARY help to replace it.

As Fairclough 2000 points out, even MODIFIERS TO STANDARD TERMINOLOGY can subtly index debate. Fairclough gives the example of a British government welfare reform proposal in which reference to "paid work" "is an implicit acknowledgement that there are other understandings (and discourses) of work" that would include unpaid labor (Fairclough 2000:181). Shifting ideas of what should count as work are also indexed when mothers are asked "Do you work outside the home?" instead of the standard phrasing, "Do you work?"

Intensifiers As was discussed in the first part of this article, in situations of opinion display intensifiers (e.g., really, surely, or indeed) mark either a debatable position (as Schiffrin 1985:40 points out) or support for a debatable position. A word like really does two things: It reaffirms the speaker's support for the position while acknowledging that others would not find that position real or true. 
This makes it appropriate for the in-between cultural standing of debatable opinions. Notice that intensifiers can be combined with hedges, as in (36), which has both the intensifier really and the hedge almost: Both are indicators of a debatable position. (See the previous discussion of hedges; multiple hedges are the hallmark of controversial opinions; a single hedge may indicate a debatable opinion.)

(35) Interview with Mathew Healey (see ex. 33).

And I really think family structure is important.

(36) Comment in focus group (see ex. 29).

... and I really feel almost personally responsible for bringing on the age of "drugs and sex and rock n' roll..."

\section{Common Opinion}

Common opinions are recognized as opinions to which alternatives exist, so they are expressed, but typically (i) in short sentences with no qualification or support. Frequently they are conveyed with (ii) clichés, maxims, and semi-formulaic expressions (Perelman \& Olbrechts-Tyteca 1969, Schiffrin 1987), and (iii) no prosodic or paralinguistic signs of hesitation. Sometimes they are given as (iv) the answer to a rhetorical question (Schiffrin 1987), (v) marked with you know (Schiffrin 1987), or (vi) expressed with taboo words or other colorful, emphatic language and emphatic stress. People who disagree with a common opinion may still invoke these cultural truths to support their own views. In such cases, there is typically either (vii) an explicit concession to some part of the common opinion, or (viii) an implicit concession indicated by borrowing and resignifying terms that represent the discourse of the common opinion.

Short sentences with no qualification or support Unlike debatable opinions, for which speakers will offer support, views judged to be the common opinion are usually given in short, unqualified sentences with no support. Indeed, the common opinion is likely to be used as support for more debatable matters of opinion:

(37) Radio talk show discussion of welfare. The caller is defending some forms of charity, such as children's toy funds. The host says that is different from welfare.

Host: It's different because we give private money specifically for that purpose. Because we're not a heartless society.

(38) Discussion in focus group of middle-aged white women about whether their children will learn to deal with the temptations of sex and drugs. Suzanne had expressed confidence that her kids will be okay.

Barbara: But it's scary. $=$

Suzanne: =It's awful. I know what's out there. My parents didn't have a clue.

Barbara: I wouldn't be their age again for a million dollars. ${ }^{29}$

(39) Interview with George Gauvin.

Big money, boy. ((Mm)) (1.0) Can't beat it. (1.2) ((Mm)) Can't beat big money. (3.0) $((\mathrm{Mm}, \mathrm{I}$ know $))$ The rich get richer and the poor get poorer. (1.8) It's true.

Clichés, maxims, and semi-formulaic expressions Clichés and maxims are formulaic expressions that usually express the common opinion in some opinion 
community. Perelman \& Olbrechts-Tyteca define a cliché as "an object of agreement regularly expressed in a certain way, a repeated formula of a stereotyped character" (1969:165), and they say about maxims that these "condense the wisdom of the nations" (1969:165). The difference between them is that while a cliché is usually popular for a short time and is marked as the outlook of the moment, maxims (aphorisms, proverbs, adages) are meant to sound timeless and carry more weight (1969:166). Maxims are unqualified generalizations expressed in complete sentences, often in the simple present tense (see Stubbs 1983:120-1 on use of the simple present tense for "eternal truths"). Sometimes a formulaic expression is combined with expressions like they say ("a quotative expression which itself conveys general consensus," Schiffrin 1987:275). Some examples of maxims I recorded in interviews about welfare or read in on-line discussions of the topic are the following: You make your bed, you sleep in it; If you play, you have to pay; It is better to teach a person how to fish than to just give fish. Not all of the common wisdom expressed in maxims is unsympathetic to welfare recipients. On the other side are Walk a mile in my shoes and There but for the grace of God go I. (Also, from a different context, The rich get richer and the poor get poorer, [39].) $)^{30}$

The following is an example of a cliché:

(40) Interview with Mathew Healey.

Now we all have to go to graduate school ((laughs)) because we're not competitive and then we'll finish graduate school and find out that we're overqualified. ((both laugh)) You know, "Would you like fries with that?"

Sometimes the common opinion is expressed in what could be called semiformulaic expressions, which are typical ways of wording a certain point of view that are not frozen enough to be called clichés. The speakers in (41) and (42) are both working-class women talking about welfare recipients:

(41) Interview with Carol Russo.

$[\mathrm{H}]$ ere are these people that sit around on their butts.

(42) Interview with Marlene Randall.

$[\mathrm{T}]$ hese young girls ... sitting on their butt.

No prosodic or paralinguistic signs of hesitation In contrast to the expression of controversial views, speakers do not hesitate if they believe their views to be the common opinion. See, for example, the latching of Suzanne's comment on Barbara's in (38) above. Notice also the paucity of verbal fillers and absence of disfluency in the form of false starts, repeated words, and self-interruptions in these examples. There are long pauses in (39); however, unlike the controversial statements in (8), (9), (16), and (23), in (39) the pauses come between clauses rather than within them, suggesting a slow speaking style rather than hesitation.

Answer to a rhetorical question It makes sense that a rhetorical questionanswer pair would express the common opinion. After all, the question would not 
be considered rhetorical if the answer were in doubt (Schiffrin 1987:278; van Dijk 1987:108).

(43) Comment in focus group of middle-aged white women.

Rosie: There could be a man and a woman who have the same degree, same knowledge, and everything else, and guess who gets the most money? It's the man.

"You know" Schiffrin found, in her interviews, that you know sometimes "marks the general consensual truths which speakers assume their hearers share through their co-membership in the same culture, society, or group" (1987:274). ${ }^{31}$ She notes this is more likely if you know is spoken with falling rather than rising intonation (1987:291). (Rising intonation turns you know into a marker of sympathetic circularity, a way for speakers to make sure hearers are with them; Bernstein 1971:111.) Of course, you know can be used in this way only if the view it marks HAS a cultural standing. There is additional support for this interpretation of you know in (44) and (45) below: In (44) you know prefaces a cliché, and in (45) you know comes before like they say and a semi-formulaic expression (it's Saturday night, they're going to go out. And raise hell.):

(44) Interview with Mathew Healey (see ex. 40).

You know, "Would you like fries with that?"

(45) Interview with Carol Russo. She is talking about the irresponsible behavior of welfare recipients.

You know, like they say, Well, it's Saturday night, they're going to go out. And raise hell.

Taboo or other colorful emphatic language and emphatic stress Unlike controversial statements, which are carefully worded to avoid offense, when speakers express what they believe to be the common opinion they may feel so confident of the view's acceptability that they strengthen it with colorful or taboo language, such as Carol Russo's and Marlene Randall's use of butt in (41) and (42). Emphasis can also be indicated vocally by pitch and stress, and in writing with an exclamation point. ${ }^{32}$

(46) Letter to the editor (M.J. Douglas, Providence Journal, 1 Sept, 1993).

I was disgusted to read the article on Juana Rivera's efforts to give her daughter an expensive coming-of-age party ... She should be sent back to wherever she came from, and good riddance! This state and this country will never be solvent until the leeches are removed from the welfare system.

(47) (Quoted in Pomerantz 1984:72). ${ }^{33}$

a:n uh by god I can' even send my kid tuh public school b'cuz they're so god damn lousy

It should be noted that in the United States, this use of "plain English" indexes a particular sort of common opinion: the common sense of the average person rather than the circumspect rhetoric of elites.

View is conceded It is typical for those who want to defend a position that is debatable or controversial to start with a concession to some part of the opposing 
common opinion (see van Dijk 1998:39 on "apparent concessions"). When opponents make this concession, it is a strong indicator that they see the propositions conceded to be widely shared. ${ }^{34}$

(48) Student newspaper op-ed essay defending the existence of God (Plaxico 1998).

Recent and exciting developments in science are telling us more every day about the intricacies of our minds, particularly the elaborate nature of the biological processes and chemical reactions that get our bodies through each day. I do not dispute these discoveries, nor do I ignore them in light of my faith.

Borrowing and resignifying terms that represent the discourse of a common opinion Opponents of the common opinion may implicitly acknowledge its widespread acceptance by borrowing and resignifying its key terms. For example, liberals acknowledge the common opinion that welfare is bad by borrowing the word welfare and resignifying it in the term corporate welfare, where it still connotes unjustified government aid, only in this case tax breaks and other financial aid to large corporations rather than cash assistance to needy individuals. Example (49) below shows exactly this liberal resignification of terms from conservative discourses, while (50) shows a conservative resignification of the liberal epithet racist:

(49) Column opposing California state bailouts of bankrupt utilities (Skelton 2001:A3, Los Angeles Times).

Moreover, the utilities have parent companies they've been supporting handsomely in recent years. It's now time for these folks to practice some self-responsibility, some family values. Parents should help their children in need—not just run them out to survive off government welfare.

(50) Headline of ad placed in several U.S. college newspapers opposing reparations for slavery (David Horowitz, quoted in Brownstein 2001:A48).

Ten Reasons Why Reparations for Slavery is a Bad Idea—and Racist Too

These may be examples of what Fairclough (1989:171) calls "destabilizing" of discourse conventions.

\section{Taken for granted}

Like all the other categories, TAKEN FOR GRANTED represents a range on the continuum of cultural standing, not a single point. At the end closer to the common opinion, propositions are expressed but are (i) presupposed rather than asserted. With increasing unanimity and movement toward what the speaker considers "facts" rather than "opinions," what is taken for granted is not expressed at all, because it does not need to be. At this far end of the cultural standing continuum, what is taken for granted really does go without saying, unlike the common opinion, which we sometimes paradoxically say with the preface, It goes without saying, but I'll say it anyway. What is unsaid because it is taken for granted can still be inferred by the analyst because it is (ii) implicit in what is said. 
Presupposed rather than asserted Linguists and philosophers of language have long defined presupposition in a way that includes cultural standing. For instance,

We shall take the view that the notion of presupposition required in discourse analysis is pragmatic presupposition, that is, "defined in terms of assumptions the speaker makes about what the hearer is likely to accept without challenge" (Givón 1979a:50). The notion of assumed "common ground" is also involved in such a characterization of presupposition and can be found in this definition by Stalnaker (1978:321):

Presuppositions are what is taken by the speaker to be the common ground of the participants in the conversation.

... it is what Grice (1981:190) terms "noncontroversial" information (Brown and Yule 1983:29).

Presupposition-triggers - words or constructions that indicate what the speaker posits as assumed common ground - include the following: definite descriptions (e.g., the worldwide recession of 2001 presupposes there was a worldwide recession in 2001); factive verbs (I realized that we were under attack presupposes that we were under attack); iteratives (Once again we have an invasion presupposes that there was a previous invasion); possessives (The governor's intransigence has jeopardized the budget process presupposes that the governor is guilty of intransigence); and cleft constructions (It wasn't the tax cut that caused the recession presupposes that something caused the recession) (Karttunen n.d., in Levinson 1983:181; Simpson 1993:125). ${ }^{35}$ Presuppositions are rife in ordinary conversation, although not always for propositions that have a cultural standing. However, if what is presupposed in an utterance does have cultural standing, that standing is likely to be high - either taken for granted or almost so. As Labov \& Fanshel note, "The more that the speakers share as common knowledge, the more they are likely to refer to such propositions rather than assert them" (1977:122). As (51) shows, propositions that are taken for granted can be embedded in utterances in which the primary assertion is framed as controversial or debatable:

(51) Focus-group conversation among middle-aged white women. The topic is causes of poverty. I think the breakdown of the family is the big factor. [PRESUPPOSED: FAMILIES HAVE BROKEN DOWN; ALSO, EVERYONE KNOWS WHAT IS MEANT BY "FAMILY," AND THERE IS A SINGLE BIG FACTOR]

(52) Question from National Opinion Research Center, General Social Survey. Are we spending too much, too little, or about the right amount on halting the rising crime rate? [PRESUPPOSED: THE CRIME RATE IS RISING] ${ }^{36}$

(53) Interview with Mathew Healey (see ex. 33).

What a family was and had worked for however many thousands of years, with all of its problems. [PRESUPPOSED: THE TRADITIONAL FAMILY HAS HAD PROBLEMS]

Unsaid but implicit in what is said What is unsaid but implicit in what is said is different from what is presupposed in the technical sense given above, which is said but in a way that backgrounds it. Some ideas are left unsaid because they are 
so controversial that they are censored. What is censored in one context, however, will be spoken in another. This differentiates it from what is unsaid because it is so taken for granted that it does not need to be said - indeed, may not even be recognized, as anthropologists and others have noticed for a long time. ${ }^{37}$ Unsaid takenfor-granted beliefs include the basic, shared schemas of culturally constructed objects and events that have been studied by cultural models researchers (e.g., Hutchins 1980, Holland \& Quinn 1987, D’Andrade \& Strauss 1992). Thus, when Mathew Healey says You know, 'Would you like fries with that?' (40), that is sufficient to convey the unsaid, taken-for-granted schemas he can assume we share about fast food jobs and low-wage service-sector work more generally, and the joke, circulating at the time, that this will be the only sort of work college graduates will be able to find. His prior remark, Now we all have to go to graduate school because we're not competitive and then we'll finish graduate school and find out that we're overqualified, also leaves unsaid various schemas about graduate training, unforgiving market economies, and a typical upper-middle-class U.S. life course in which it is taken for granted that one is competing for the sorts of jobs for which graduate training might give one an edge. Such discussions of human behavior rely as well on implicit person concepts (in this case, that people make career choices based on economic rewards; see Strauss 2000 for discussion of conflicting person concepts implicit in the way Americans talk about class). Denials (e.g., No one was put aside because they weren't important or didn't work on Capitol Hill [6] and we're not a heartless society [37]) rely on the implicit assumption that what is being denied is bad. When speakers give evidence to support a position, they implicitly assume that this kind of evidence can be trusted. When they discuss one topic in connection with another, without any explanation for the connection, they take for granted the cultural models that explain the connection. Thus, in the student op-ed essay defending religious beliefs (48), the writer takes pains to affirm her belief in neurobiology and physiology, though without explaining why these are relevant. In the university opinion community for which she is writing, the belief that the findings of science have some bearing on whether religious claims are to be believed is just taken for granted. (See D'Andrade n.d. and Quinn n.d. for detailed discussions of how to extract implicit cultural models from interviews.)

\section{O N C L U S I O N}

There are various reasons why application of this model to discourse is not as straightforward as the previous discussion makes it appear. First, speakers may deliberately inflate or deflate the cultural standing of their views. In one conversation I witnessed, the speaker stated a view that was highly debatable, if not controversial, in a completely unmodalized way (Where is Bin Laden? Why haven't we captured him yet? If Clinton was still president, we'd have him by now!). In that context, it was clear that he did so to needle his addressee, whom he knew to have a low opinion of the former president. Such deliberate failures to mark 
cultural standing appropriately are not a problem for the model. Like Grice's conversational maxims, they are intended to create implicatures - in this case, about the playfully competitive key of the exchange.

Another complication is that cultural standing is always relative to the opinion community that is most salient for a speaker in a given situation. This depends in part on the kind of communicative event that is occurring. When offending the addressee has potentially serious consequences, speakers are likely to use the markers that are appropriate given what they guess to be the view's standing in the hearer's opinion community. In those situations and in ones where speakers have time to prepare (e.g., written utterances, rehearsed speeches), it is rare to find slip-ups of the sort illustrated in (1), in which S first expressed standing in his own community without regard to what he thought was mine. When the larger ends of the conversation are to express, strengthen, or reinforce intimacy, S's and H's shared opinion community (i.e., the opinion community S thinks they share) will be paramount. If the speaker does not particularly care what the addressee thinks (as is sometimes true of participants in social science interviews), the relevant opinion community is more likely to be the general public. An interesting topic for future research is what happens when two or more opinion communities are salient for the speaker. I have found that speakers have particular ways of indicating that a view is the common opinion in the larger society but not in the opinion community they share with the addressee, a special variety of the common opinion best termed the CONVENTIONAL WISDOM. For example, Nancy Goodall recited some of the conventional wisdom about welfare mothers in a sing-song voice. Her sing-song intonation framed the views as common while mocking them as trite (Strauss n.d.). Other conventional wisdom markers are scare quotes (both in print and in the "quote" finger gesture; see Fairclough 1989:89) and expressions like so-called and supposedly. ${ }^{38}$

In the majority of the examples given above, there were not great differences in authority between speaker and addressee with respect to the topic at hand. Would the presence of such differences (e.g., teachers lecturing to students, political leaders addressing the public, parents informing their children) affect the way cultural standing was marked? The cultural standing model presented above predicts that if there is no potential danger to S's appearance as knowledgeable about the cultural standing of the views espoused (e.g., parents do not usually worry that their preschool children will know that their values are controversial in the wider society), then $\mathrm{S}$ would be less likely to mark controversial or disputable views in the ways indicated above. As Sperber \& Wilson note, "The communicator may be in a position of such authority over her audience that the success of her informative intention is mutually manifest in advance. Journalists, professors, religious or political leaders assume, alas often on good grounds, that what they communicate automatically becomes mutually manifest" (1986:63).

There seem to be genre differences as well, and these pose a greater problem for the model. For example, my preliminary investigation of letters to the editor 
and on-line bulletin boards suggests that, in this context, controversial or debatable opinions are often stated without mitigation, just like the common opinion. This may be so because the context is by definition one for expressing debatable and controversial views, so no further markers of that are necessary. Still, it may be necessary to modify the scheme presented above to adapt it to different genres and communicative events.

Finally, there are various ways in which this model might not be universal. For example, some languages may have linguistic resources, or discourse practices, absent in English that could be used as cultural standing markers. Given the overlap between discourse markers of epistemic modality and cultural standing, it may turn out, for example, that the evidential morphemes present in some languages can also serve as cultural standing markers. Similarly, discourse practices in U.S. speech communities - such as use of the first person to preface debatable opinions (I think, in my opinion) - might be avoided in other speech communities (e.g., in Japan; Yamada 1997:90; see also Bernstein 1971:98 on greater middle-class than working-class use of I think in his British sample, and Besnier 1992:167 on the way knowledge is always framed as shared rather than personal on Nukulaelae Atoll). Or there may be greater use, as Goffman comments in comparing "folk communities" with middle-class Americans, of "adages, sayings, little homilies, and the like" to convey "the wisdom of the people" (1974:522). In many societies, the ability to express one's opinion indirectly, in highly allusive language, is greatly valued (see Hobart 1975, Keenan 1975, Strathern 1975, and Sherzer 1989 on Balinese, Malagasy, Melpa, and Cuna oratory, respectively). We might find that a close attention to expression of controversial opinions in such societies could lead to much greater detail under the general heading of "self-censoring or using euphemisms or other indirect language."

It would not be surprising if points along the continuum were spaced differently in different speech communities. For example, in speech communities that avoid conflict, a view may not need to be very controversial to be marked as controversial, while among speech communities that have a high tolerance for conflict and debate (e.g., Israel; Blum-Kulka 1982, cited in Wierzbicka 2002:242), the scale could be skewed the other way, with views that are controversial being treated as if they were simply debatable, and debatable views as the common opinion. There could be historical shifts, as well, in expectations about how cultural standing is to be marked (Salager-Meyer et al. 1996).

Such cross-cultural differences in the way cultural standing is marked do not negate the potential universal that a cultural standing continuum will be recognized and marked IN SOME WAY everywhere. For example, Hobart explains that in the south Balinese village council meetings he observed, an address was expected to include nyelasang, "a restatement of common knowledge or a repetition of universally accepted values on the subject under debate," before ngèdèngang pemineh pedidi, “a brief statement of the current speaker's opinion" (1975:75). Furthermore, "Speeches which rely heavily on the promulgation of social ideals 
may well propound contrasting or contradictory views," (1975:75n), a strategy that recalls my observation, "It is typical for those who want to defend a position that is debatable or controversial to start with a concession to some part of the opposing common opinion." Acknowledging that one example from another society is not sufficient to establish the point, and aware of potential skepticism from my readers, I will close with a claim I mark as debatable: It is my view that in every speech community there will be some way of marking cultural standing. ${ }^{39}$

\section{NOTES}

* I am grateful for helpful comments from Jane Hill and two anonymous reviewers for Language in Society as well as Justin Beck, Paul Ireland, Ronald Macaulay, Naomi Quinn, Daniel Segal, James Van Cleve, other students in Methods of Discourse Analysis (spring 2001) and Language and Power (spring 2003), and other colleagues who commented on the paper when I presented it at Pitzer College in February 2000.

${ }^{1}$ In the flat earth example, clearly part of the problem is the view that is held, not just how it is worded. But wording makes a difference. If the view had been marked as controversial by attributing it to another, less responsible version of the self (In my stranger moments I almost think that ...) or acknowledged as controversial or attributed to another source (I know it's hard to believe, but I've heard some authorities really think that....), we would be more inclined to take S seriously.

${ }^{2}$ Wierzbicka (2002:240-1) claims this is an Anglo trait not found in many other European countries.

${ }^{3}$ Hymes's discussion does not refer to conversation analysis explicitly. I have taken that interpretation from Duranti (1997:265).

${ }^{4}$ This would be a subtype of Brown \& Levinson's positive politeness strategy 4, "Use in-group identity markers."

${ }^{5}$ This seems obvious, but it is missing from Brown \& Levinson's analysis. Thus, they give as examples of acts "that show that S doesn't care about (or is indifferent to) H's positive face" "raising of dangerously emotional or divisive topics, e.g., politics, race, religion, women's liberation" (pp. 66, 67). Whether those topics are divisive, of course, depends on their standing in S and H's opinion communities.

${ }^{6}$ All names of interviewees and focus group participants are pseudonyms.

${ }^{7}$ My transcription conventions are as follows:

! animated tone

(time) timed pause in seconds (any indicated backchannels, gestures, etc. occurred during the pause)

... deletion

- $\quad$ self interruption

$=\quad$ latching, i.e., no perceptible pause between turns

: lengthened syllable

italics speaker's emphasis

boldface highlighted for analysis

( ) unintelligible syllables

(word?) uncertain transcription

(( )) Contextual, prosodic, and paralinguistic information or backchannel signals from other participants

[ ] paraphrase

${ }^{8}$ Bakhtin called reaction to previous discourse about the object "the dialogic relationship toward an alien word within the object" (1981:283). Anticipation of the listener's response and reaction to previous discourse are two varieties of what he called "internal dialogism," i.e., dialogism that is not part of an obvious dialogue between two characters.

${ }^{9}$ I am grateful that Jane Hill alerted me to Givón's work after this article was accepted for publication but while there was still time to incorporate it into my revisions.

${ }^{10}$ For the most part, Labov \& Fanshel's (1977:100) classification A-events (known to A, but not to B), B-events (known to B, but not to A), etc., focuses on epistemic concerns as well. Their categories of AB-events (known to both $\mathrm{A}$ and $\mathrm{B}$ ), O-events (known to everyone present), and D-events 
(known to be disputable) are relevant to the present discussion, but their primary concern is with how interlocutors are supposed to respond to each of these, not how speakers frame them.

${ }^{11}$ In addition to the obvious hedge words highlighted above, a designer drug based on ecstasy and without the scary side effects also indicate low speaker commitment to the view that ecstasy itself has benefits.

${ }^{12}$ Hyland's insightful discussion shows awareness of cultural standing issues: "It is clear in the following extracts, for example, what propositions the writers consider to be established knowledge, and what they regard as more contentious" (1998:351); and "By employing markers of evidentiality with inclusive pronouns, for instance, writers are able to construct a shared context with their readers and draw on assumed beliefs specific to their particular social group" (1998:367). Lacking a general model of cultural standing, however, he relies more heavily on politeness theory than his data warrant.

${ }^{13}$ Thus, although Stubbs's definition of modality in terms of commitment or detachment, which "concerns whether a proposition is presented as true, false, self-evident, a matter of objective fact or of subjective opinion, shared knowledge, taken for granted or debatable, controversial, precise or vague, contradictory to what others have said and so on" (1996:204-5) overlaps with the notion of cultural standing, they are not the same.

${ }^{14}$ Givón's category of the "taken for granted," for example, seems to include both the orthodox view and beliefs that are doxic. This confusion occurs frequently, despite the fact that the distinction between what is explicitly believed and what is tacitly held has a long history in anthropology, going back to Boas 1938 and Kluckhohn 1941, 1943.

${ }^{15}$ One reviewer of this article questioned how well Bourdieu's categories lined up with mine, noting that in Bourdieu's account, "The doxic gets disrupted by heterodoxy, and then orthodoxy swings in in counterreaction." Bourdieu does discuss this kind of historical progression (e.g., 1977: 168-9). However, historical order need not replicate cultural standing order, even if this sort of historical progression were normally the case, which is not clear.

${ }^{16}$ Dan Segal has pointed out (personal communication, February 2000) that there is a fifth option: views that are so far from the cultural realm of possibilities that they are "off the chart." That is useful to keep in mind, but I will not discuss them here because by their very nature they are not discussed, and hence lack standard markers in discourse.

${ }^{17}$ It follows that for a great many topics, children would not be part of an opinion community.

${ }^{18}$ The primary data drawn on in this article are taped semistructured interviews about the welfare system that I conducted in 1995 with a diverse sample of 16 Rhode Island residents, as well as interviews I conducted in 1985 and 1990 with Rhode Islanders about issues of class mobility and corporate behavior, and one of many interviews I conducted in 2000 for similar research in North Carolina; a 1994 focus group on the topic of welfare I moderated with nine white women ranging in age from 39 to 56; 60 on-line message board postings collected on 26 June 1995 from America On Line's "Access Point" message board on welfare reform; a tape recording of the Mary Ann Sorrentino radio talk show, 2 August 1993; and letters to the editor on the topic of welfare reform. Examples taken from meetings or chance encounters were based on my notes, rather than tape recordings. In those cases, I have asked for the speakers' permission to use their words, if I thought they could be identified.

${ }^{19}$ See Fairclough 2000 for analysis of welfare reform discourse in Britain during the same period.

${ }^{20}$ Transcript based on notes. Ironically, the tape had ended before this point.

${ }^{21}$ Credentialing remarks like I am not an $x$ but ... seem to function the same way as lamination, discussed below: If you recognize that your behavior seems problematic, you must be more openminded than your comments would otherwise make you appear.

${ }^{22}$ This makes hedges one type of modalizer. Phrases that serve to mitigate in the particular context but do not normally have that function (e.g., a designer drug based on ecstasy and without the scary side effects in [4]) are not hedges by that definition. (See Markkanen \& Schröder 1997:7 on the question of how hedges relates to modalizers.) I can see using hedge as a verb (hedged, hedging) in a broader way that is synonymous with modalizing, as Markkanen \& Schröder propose (1989, discussed in Markkanen \& Schröder 1997:5).

${ }^{23}$ There is insufficient recognition of the function of hedges to mark cultural standing. See, for example, Channell 1994, which lists ten functions of vague language, but omits low cultural standing.

${ }_{24}$ The unstated agent of It is said seems to be a weighty authority that does not need to be named, whereas the unstated agent of It could be said seems purely hypothetical.

${ }^{25}$ The article makes it clear that this view is controversial: "After a few nervous glances, the diners went around the table, each offering a similar confession. Few would say so in public, however." 
${ }^{26}$ Yamada (1997:90) gives this as an example of a characteristically Japanese technique for signaling reluctant disagreement, but it is used by Americans as well, as in example (24).

${ }^{27}$ Schiffrin suggests that "coordinating conjunctions (and, so, but) often introduce the position, and subordinating conjunctions (because, like) often introduce the support" (1985:39; see also Schiffrin 1987).

${ }^{28}$ Schiffrin gives the following explanation of the special place of beliefs: "Beliefs, opinion, judgments, and feelings differ from assertions and statements of fact because they are representations of internal, cognitive states that are available for neither observation nor verification. Even when presented in a conversation, then, they remain the special informational preserve of the speaker. Note, however, a paradox: Because beliefs are the speaker's informational property, the speaker's right to maintain them cannot be denied, but because they are unavailable for proof, neither can others' rights to doubt their validity be denied" (1985:40). I would modify this statement a little. "Assertions and statements of fact" are also presentations of beliefs - the difference is not whether a belief is being presented, but what speakers see as its cultural standing. Thus, to gain the right of incorrigibility it is not enough to utter a belief. It has to be EXPLICITLY MARKED AS THE SPEAKER's BELIEF by saying I believe, I think, and so on. No one can doubt that is what you believe, even if they disagree with the assertion.

${ }^{29}$ My parents didn't have a clue and I wouldn't be their age again for a million dollars, if taken to refer just to the speaker's experience, are not the common opinion. Note, however, that they are expressed in short, unqualified sentences, probably because the speakers assume their reactions are shared by the other women there.

${ }^{30}$ These examples show that there can be a variety of conflicting "common opinions" on a topic.

${ }^{31}$ Schiffrin credits T. Labov 1980 with a similar point. There is a large literature on you know. (See Tree \& Schrock 2002 for a summary that is consistent with the point developed here.) By contrast, Macaulay's analysis of Scottish speakers finds you know use varying idiosyncratically and seeming to function in "the rhythmic organization of utterances, particularly when it is used at the end of an utterance" (2002:17).

32 The emphatic stress used in the common opinion needs to be distinguished from the contrastive stress of the debatable opinion. Contrastive stress is more selective within a clause or sentence, picking out only the particular words or phrases that are highlighted as different from other opinions.

33 Pomerantz does not comment on the use of by god and god damn here.

${ }^{34}$ As Perelman \& Olbrechts-Tyteca point out, 'Such expressions as 'although,' 'in spite of,' and 'doubtless' indicate that one is making certain concessions but their main function, depending particularly on their position in the phrase, is to show the degree of importance attached to what is conceded" (1969:157).

${ }^{35}$ Although subordinate clauses are also presupposed in the way most linguists define this term, this construction is a less reliable marker of cultural taken-for-granteds.

${ }^{36}$ In 1984, this question was replaced with the more neutral wording, "Are we spending too much, too little, or about the right amount on law enforcement?" A question about spending on "solving the problems of the big cities" was changed to one about spending on "assistance to big cities." A very interesting study of changes in cultural standing could be made by examining the wording of questions in national opinion surveys.

${ }^{37}$ This does not exhaust the types of unsaids. There is also what is unsaid because it is not part of the cultural realm of possibilities ("off-the-chart" views, see n. 16), and the unsaid of what is not easily voiced because it is known only in a fragmentary, disconnected, or experiential way (Strauss \& Quinn 1997:39).

${ }^{38}$ As Dan Segal has pointed out to me, other dimensions intersect with cultural standing - for example, whether the view should be treated seriously or not (personal communication, March 2002).

${ }^{39}$ Cf. Skelton 1988 and Kubui 1988, both cited in Salager-Meyer et al. (1996:167), on the universality of hedging.

\section{REFERENCES}

Bakhtin, Mikhail M. (1981). Discourse in the novel. In Michael Holquist (ed.), The dialogic imagination, 259-422. Austin: University of Texas Press.

Balaban, Victor (2000). The Virgin Mary, the apocalypse, and the Internet: A cognitive linguistic analysis of discourse at a Marian apparition site. Dissertation, Emory University.

Language in Society 33:2 (2004) 
Bernstein, Basil (1971). Class, codes and control: Theoretical studies towards a sociology of language. New York: Schocken.

Besnier, Niko (1992). Reported speech and affect on Nukulaelae Atoll. In Jane H. Hill \& Judith T. Irvine (eds.), Responsibility and evidence in oral discourse, 161-81. Cambridge: Cambridge University Press.

Blum-Kulka, Shoshana (1982). Learning to say what you mean in a second language: A study of the speech act performance of learners of Hebrew as a second language. Applied Linguistics 3:29-59.

Boas, Franz (1938). The mind of primitive man. Rev. ed. New York: Free Press.

Bourdieu, Pierre (1977). Outline of a theory of practice. Richard Nice, trans. Cambridge: Cambridge University Press.

Boyce, Nell (2001). Ecstatic? Maybe. But not without risks. U.S. News \& World Report, 5 February 2001:16.

Brown, Gillian, \& Yule, George (1983). Discourse analysis. Cambridge: Cambridge University Press.

Brown, Penelope, \& Levinson, Stephen C. (1987). Politeness: Some universals in language usage. Cambridge: Cambridge University Press.

Brownstein, Andrew (2001). Race, reparations, and free expression. Chronicle of Higher Education, 30 March 2001:A48-A50.

Chafe, Wallace, \& Nichols, Johanna (eds.) (1986). Evidentiality: The linguistic coding of epistemology. Norwood, NJ: Ablex.

Channell, Joanna (1994). Vague language. Oxford: Oxford University Press.

Chen, Rong (2001). Self-politeness: A proposal. Journal of Pragmatics 33:87-106.

Comaroff, Jean, \& Comaroff, John (1991). Of revelation and revolution: Christianity, colonialism, and consciousness in South Africa, Vol. 1. Chicago: University of Chicago Press.

D’Andrade, Roy G. (1987). A folk model of the mind. In Dorothy Holland \& Naomi Quinn (eds.), Cultural models in language and thought, 112-48. Cambridge: Cambridge University Press.

(n.d.) Some methods for studying cultural cognitive structures. In N. Quinn (ed.), Finding culture: Methods for the cultural analysis of talk. To appear, New York: Palgrave.

\& Strauss, Claudia (1992) (eds). Human motives and cultural models. Cambridge: Cambridge University Press.

Duranti, Alessandro (1997). Linguistic anthropology. Cambridge: Cambridge University Press.

Ehrenreich, Barbara (2000). Class ceiling. Independent, 5-11 January 2000:15-17. [First printed in In these Times.]

Fairclough, Norman (1989). Language and power. London: Longman. (1992). Discourse and social change. Cambridge: Polity.

(2000). Discourse, social theory, and social research: The discourse of welfare reform. Journal of Sociolinguistics 4:163-95.

Garvey, Megan, \& Rosenblatt, Robert A. (2001). Anthrax fears in a 911 call. Los Angeles Times, 8 November 2001:A1, A15.

Givón, Talmy (1979). On understanding grammar. New York: Academic Press. (1982). Evidentiality and epistemic space. Studies in Language 6:23-49.

Goffman, Erving (1959). The presentation of self in everyday life. Garden City, NY: Doubleday. (1967). Interaction ritual: Essays on face-to-face behavior. New York: Pantheon. (1974). Frame analysis: An essay on the organization of experience. Cambridge, MA: Harvard University Press. Press.

(1981). Radio talk. In his Forms of talk, 197-330. Philadelphia: University of Pennsylvania

Grice, Paul (1981). Presupposition and conversational implicature. In Peter Cole (ed.), Radical pragmatics, 183-98. New York: Academic Press.

Halliday, Michael A. K. (1976). Modality and modulation in English. In Gunther R. Kress (ed.), Halliday: System and function in language, 189-213. London: Oxford University Press.

Hewitt, John P., \& Stokes, Randall (1975). Disclaimers. American Sociological Review 40:1-11.

Hill, Jane H. (1995). The voices of Don Gabriel: Responsibility and self in a modern Mexicano narrative. In Dennis Tedlock \& Bruce Mannheim (eds.), The dialogic emergence of culture, 97147. Urbana: University of Illinois Press.

(n.d.) Finding culture in narrative. In Naomi Quinn (ed.), Finding culture: Methods for the cultural analysis of talk. To appear, New York: Palgrave. 
\& Zepeda, Ofelia (1992). Mrs. Patricio's trouble: The distribution of responsibility in an account of personal experience. In Jane H. Hill \& Judith T. Irvine (eds.), Responsibility and evidence in oral discourse, 197-225. Cambridge: Cambridge University Press.

Hobart, Mark (1975). Orators and patrons: Two types of political leader in Balinese village society. In Maurice Bloch (ed.), Political language and oratory in traditional society, 65-92. London: Academic Press.

Hodge, Robert, \& Kress, Gunther (1988). Social semiotics. Cambridge: Polity.

Holland, Dorothy, \& Quinn, Naomi (1987) (eds.). Cultural models in language and thought. Cambridge: Cambridge University Press.

Hutchins, Edwin (1980). Culture and inference: A Trobriand case study. Cambridge, MA: Harvard University Press.

Hyland, Ken (1998). Boosting, hedging and negotiation of academic knowledge. Text 13: 349-82.

Hymes, Dell (1974). Foundations in sociolinguistics: An ethnographic approach. Philadelphia: University of Pennsylvania Press.

Karttunen, Lauri (n.d.). Presuppositional phenomena. Ms., Department of Linguistics, University of Texas, Austin.

Keenan, Elinor (1975). A sliding sense of obligatoriness: The polystructure of Malagasy oratory. In Maurice Bloch (ed.), Political language and oratory in traditional society, 93-112. London: Academic Press.

Kerr, Bob (1993). The protesting poor deserve to be there. Providence Journal, 6 December 1993 : E1-2.

Kluckhohn, Clyde (1941). Patterning as exemplified in Navaho culture. In Leslie Spier et al. (eds.), Language, culture, and personality: Essays in memory of Edward Sapir, 109-30. Menasha, WI: Sapir Memorial Publication Fund.

(1943). Covert culture and administration problems. American Anthropologist 45:213-27.

Kress, Gunther, \& Hodge, Robert (1979). Language as ideology. London: Routledge \& Kegan Paul.

Kubui, A. (1988). Aspects of hedgings in the discussion of medical English discourse. Dissertation, University of Aston in Birmingham.

Labov, T. (1980). The communication of morality: Cooperation and commitment in a food cooperative. Dissertation, Columbia University.

Labov, William, \& Fanshel, David (1977). Therapeutic discourse: Psychotherapy as conversation. New York: Academic Press.

Lakoff, George (1972). Hedges: A study in meaning criteria and the logic of fuzzy concepts. In Papers from the Eighth Regional Meeting, Chicago Linguistic Society, 183-228. Chicago: Chicago Linguistic Society.

Levinson, Stephen C. (1983). Pragmatics. Cambridge: Cambridge University Press.

Lyons, John (1977). Semantics, Vol. 2. Cambridge: Cambridge University Press.

Macaulay, Ronald (2002). You know, it depends. Journal of Pragmatics 34:749-67.

McIlvenny, Paul (1996). Popular public discourse at speakers' corner: Negotiating cultural identities in interaction. Discourse and Society 7:7-37.

Markkanen, Raija, \& Schröder, Hartmut (1989). Hedging as a translation problem in scientific texts. In C. Laurén \& M. Nordman (eds.), Special languages: From human thinking to thinking machines, 171-75. London: Multilingual Matters.

(1997). Hedging: A challenge for pragmatics and discourse analysis. In Raija Markkanen \& Hartmut Schröder (eds.), Hedging and discourse: Approaches to the analysis of a pragmatic phenomenon in academic texts, 3-18. Berlin: Walter de Gruyter.

Myers, Greg (1989). The pragmatics of politeness in scientific articles. Applied Linguistics 10:1-35. 27:85-111.

Noelle-Neumann, Elisabeth (1993). The spiral of silence: Public opinion - our social skin. 2nd ed. Chicago: University of Chicago Press.

Overstreet, Maryann, \& Yule, George (2001). Formulaic disclaimers. Journal of Pragmatics 33:45-60.

Perelman, Chaïm, \& Olbrechts-Tyteca, Lucie (1969). The new rhetoric: A treatise on argumentation. John Wilkinson \& Purcell Weaver, trans. Notre Dame: University of Notre Dame Press.

Plaxico, Ashley (1998). To find God, look no further than your own conscience. The Chronicle (Duke University), 22 October 1998:10. 


\section{CLAUDIA STRAUSS}

Pomerantz, Anita (1984). Agreeing and disagreeing with assessments: Some features of preferred/ dispreferred turn shapes. In J. Maxwell Atkinson and John Heritages (eds.), Structures of social action: Studies in conversation analysis, 57-101. Cambridge: Cambridge University Press.

Quinn, Naomi (n.d.). How to reconstruct the schemas people share, from what they say. In Naomi Quinn (ed.), Finding culture: Methods for the cultural analysis of talk. To appear, New York: Palgrave.

Ruddick, Lisa (2001). The near enemy of the humanities is professionalism. Chronicle of Higher Education, 23 November 2001:B7-9.

Sacks, Harvey (1987). On the preferences for agreement and contiguity in sequences in conversation. In Graham Button \& John Lee (eds.), Talk and social organization, 54-69. Clevedon: Multilingual Matters.

Salager-Meyer, Françoise; Defieves, Gérard; \& Manelynck, Miguel (1996). Epistemic modality in 19th and 20th century medical English written discourse: A principal component analysis study. Interface 10:163-97.

Schegloff, Emanuel A.; Jefferson, Gail; \& Sacks, Harvey (1977). The preference for self-correction in the organization of repair in conversation. Language 53:361-82.

Schiffrin, Deborah (1985). Everyday argument: The organization of diversity in talk. In Teun van Dijk (ed.), Handbook of discourse analysis, vol. 3, 35-46. London: Academic Press.

(1987). Discourse markers. Cambridge: Cambridge University Press.

Sherzer, Joel (1989). Namakke, Sunmakke, Kormakke: Three types of Cuna speech event. In Richard Bauman \& Joel Sherzer (eds), Explorations in the ethnography of speaking, 263-82. 2nd ed. Cambridge: Cambridge University Press.

Simpson, Paul (1993). Language, ideology and point of view. London: Routledge.

Skelton, George (2001). A clear voice cuts through all the energy crisis static. Los Angeles Times, 8 February 2001:A3.

Skelton, John (1988). The care and maintenance of hedges. English Language Teaching Journal 42:37-43.

Sperber, Dan, \& Wilson, Dierdre (1986). Relevance: Communication and cognition. Cambridge: Harvard University Press.

Stalnaker, Robert C. (1978). Assertion. In Peter Cole (ed.), Syntax and semantics 9: Pragmatics. New York: Academic Press.

Strathern, Andrew (1975). Veiled speech in Mount Hagen. In Maurice Bloch (ed.), Political language and oratory in traditional society, 185-203. London: Academic Press.

Strauss, Claudia (2000). The culture concept and the individualism/collectivism debate: Dominant and alternative attributions for class in the United States. In Larry Nucci et al. (eds.), Culture, thought, and development, 85-114. Mahwah, NJ: Lawrence Erlbaum.

(n.d.). Analyzing discourse for cultural complexity. In Naomi Quinn (ed.), Finding culture. To appear, New York: Palgrave.

, \& Quinn, Naomi (1997). A cognitive theory of cultural meaning. Cambridge: Cambridge University Press.

Stubbs, Michael (1983). Discourse analysis: The sociolinguistic analysis of natural language. Chicago: University of Chicago Press.

(1996). Text and corpus analysis: Computer-assisted studies of language and culture. Oxford: Blackwell.

Tree, Jean E. Fox, \& Schrock, Josef C. (2002). Basic meanings of you know and I mean. Journal of Pragmatics 34:727-47.

van Dijk, Teun A. van (1987). Communicating racism: Ethnic prejudice in thought and talk. Newbury Park, CA: Sage.

(1998). Opinions and ideologies in the press. In Allan Bell \& Peter Garrett (eds.), Approaches to media discourse. Oxford: Blackwell.

Wierzbicka, Anna (2002). Right and wrong: From philosophy to everyday discourse. Discourse Studies 4:225-52.

Williams, Raymond (1977). Marxism and literature. London: Oxford University Press.

Yamada, Haru (1997). Different games, different rules: Why Americans and Japanese misunderstand each other. New York: Oxford University Press.

(Received 10 June 2002, accepted 31 October 2002, final revision received 4 June 2003) 